\title{
LANTING
}

\section{PUSAT SENI BELADIRI KUNTAU DI DESA BARIKIN}

\author{
M. Mustaqim Azmi \\ Program Studi Teknik Arsitektur Fakultas Teknik Universitas Lambung Mangkurat \\ 1610812310009@mhs.ulm.ac.id
}

\section{Bani Noor Muchamad}

Program Studi Teknik Arsitektur Fakultas Teknik Universitas Lambung Mangkurat bani.nm@ulm.ac.id

\begin{abstract}
ABSTRAK
Pusat Seni Beladiri Kuntau di Desa Barikin merupakan sebuah sarana yang mewadahi masyarakat sekitar dalam mempelajari, mengembangkan dan melestarikan kesenian beladiri lokal khas banjar. Permasalahan arsitektur yang diangkat pada laporan ini adalah bagaimana perancangan pusat seni beladiri kuntau khas banjar yang dapat mewadahi aktivitas pelatihan dan pertunjukan kuntau. Konsep yang diajukan untuk perancangan adalah konsep Budaya Pendidikan Rekreasi dengan pendekatan Arsitektur Regional berbasis Vernakular. Konsep ini mengangkat karakter dari budaya kuntau dan budaya banjar ke dalam wujud bangunan pusat seni beladiri. kuntau.
\end{abstract}

Kata kunci: Pusat Seni Beladiri, Kuntau, Banjar.

\section{ABSTRACT}

The Kuntau Martial Arts Center in Barikin Village is a facility that accommodates the local community in learning, developing and preserving the local Banjar martial arts. The architectural problem raised in this report is how the design of the banjar's typical kuntau martial arts center can accommodate training activities and kuntau performances. The concept proposed for the design is the concept of a Cultural Education Recreation with a Vernakular-based Regional Architecture approach. This Concept raises the character of kuntau culture and banjar culture into the form of kuntau martial arts center building.

Keywords: Martial Arts Center, Kuntau, Banjar.

\section{PENDAHULUAN}

Barikin dikenal sebagai desa budaya yang menjadi kiblat kesenian tradisional di Kalimantan Selatan. Desa ini berada di Kecamatan Haruyan, Kabupaten Hulu Sungai Tengah, Provinsi Kalimantan Selatan. Kebanyakan kesenian tradisional Banjar atau Kalimantan Selatan khususnya seni pertunjukan terdapat di Desa Barikin.
Salah satu tokoh yang berperan dalam pembinaan, pengembangan dan pelestarian kesenian tradisional Banjar di desa adalah A. W. Syarbaini (1955-2016).

Salah satu keseniannya adalah seni beladiri kuntau khas Banjar. Kuntau merupakan beladiri yang berasal dari China dan dibawa ke Asia Tenggara pada masa lalu. Di Indonesia Kuntau dijadikan bekal 
oleh masyarakat dalam melakukan perlawanan terhadap penjajahan Belanda. Kemudian Kuntau berkembang menjadi warisan budaya masyarakat Indonesia. Kuntau lambat laun melebur dengan kearifan lokal setiap daerahnya sehingga kuntau kini di setiap daerahnya memiliki ciri khasnya masing-masing.

Dijaman sekarang ini kuntau masih cukup terdengar gaungnya meski kalah terkenal dan peminatnya dibandingkan beladiri yang lain. Di Kalimantan Selatan sendiri seni beladiri ini cukup banyak peminatnya yang tersebar di kota dan kabupaten seperti di Banjarmasin, Barjarbaru, Barito Kuala, Tapin, Hulu Sungai Selatan, Hulu Sungai Tengah, Hulu Sungai Utara, Balangan dan Tabalong.

Di Kabupaten Hulu Sungai Tengah berdiri sebuah komunitas Kuntau khas Banjar yaitu Komunitas Persaudaraan Kuntau Borneo (Kompak Borneo). Komunitas ini mewadahi lebih dari 20 perguruan Kuntau khas Banjar yang tersebar di Kabupaten ini dengan anggota yang sudah sudah terdaftar lebih dari 500 anggota.

Berdasarkan wawancara dengan Abdul Manan ketua Kompak Borneo secara garis besar kendala yang mereka hadapi adalah :

Seni beladiri kuntau khas Banjar ini masih kalah terkenal dari beladiri lain dikarenakan kurang adanya publikasi baik secara langsung maupun tidak langsung.

Hampir semua perguruan Kuntau yang ada masih belum memiliki tempat latihan yang layak dan memadai. Mereka biasanya latihan di lapangan sepakbola, halaman sekolah dan halaman rumah guru yang melatihnya.

Perguruan kuntau khas Banjar yang tergabung di Kompak Borneo berencana melakukan latihan gabungan akan tetapi masih terkendala tempat yang belum memadai.
Oleh karena itu perlu adanya suatu tempat dimana masyarakat dapat mengenal dan mengembangkan seni beladiri Kuntau khas Banjar dan juga sebagai wadah pelestarian seni beladiri tradisional supaya tidak hilang dimakan oleh zaman.

\section{PERMASALAHAN}

Berdasarkan data-data yang didapatkan dan latar belakang, maka didapatkan permasalahan arsitektural sebagai berikut :

Bagaimana perancangan pusat seni beladiri Kuntau khas Banjar yang dapat mewadahi aktifitas pelatihan dan pertunjukan Kuntau?.

\section{TINJAUAN PUSTAKA}

\section{A. Pengertian Judul}

Pusat seni beladiri kuntau di Desa Barikin adalah suatu tempat yang mewadahi aktifitas pelatihan dan pertunjukan seni beladiri Kuntau khas Banjar yang berada di Desa Barikin Kecamatan Haruyan Kabupaten Hulu Sungai Tengah Provinsi Kalimantan Selatan.

\section{B. Metode Perancangan}

Pada perancangan bangunan "Pusat Seni Beladiri Kuntau di Desa Barikin" metode yang dipilih dalam penyelesaian masalah kali ini adalah dengan pendekatan arsitektur regional berbasis vernakular.

Regionalisme dapat didefinisikan sebagai suatu kesadaran untuk membuka kekhasan tradisi dalam merespon terhadap tempat dan iklim, kemudian melahirkan identitas formal dan simbolik ke dalam bentuk kreatif yang baru menurut cara pandang tertentu dari pada lebih berhubungan dengan kenyataan pada masa itu dan berakhir pada penilaian manusia.

Adapun ciri - ciri daripada arsitektur regionalis adalah menggunakan bahan bangunan lokal dengan teknologi modern, tanggap dalam mengatasi pada kondisi iklim setempat, mengacu pada tradisi, warisan 
sejarah serta makna ruang dan tempat, mencari makna dan substansi kultural, bukan gaya/ style sebagai produk akhir.

Secara umum wilayah arsitektur regional berbasis vernakular yang dipilih adalah Kalimantan Selatan, Kalimantan Selatan yang mayoritas penduduknya adalah suku Banjar memiliki ciri khas arsitekturnya tersendiri seperti bentuk rumah dan struktur bangunannya.

Sedangkan secara khususnya wilayah arsitektur regional berbasis vernakular yang dipilih adalah Desa Barikin. Desa Barikin merupakan desa yang menjadi kiblat kesenian tradisional Kalimantan Selatan karena terdapat banyak kesenian khas Banjar yang lahir dan berkembang di desa ini.

\section{PEMBAHASAN}

\section{A. Lokasi}

Site ini memiliki luas $\pm 29.700 \mathrm{~m} 2$ dan berada di sisi JI. A. Yani dan JI. Raya Haruyan Desa Barikin Kecamatan Haruyan Kabupaten Hulu Sungai Tengah.. Site ini memiliki 5 kriteria yang dibutuhkan dalam perancangan yakti sesuai dengan pola ruang Kabupaten Hulu Sungai Tengah, berdekatan dengan area pendidikan, memiliki unsur lokal, akses yang mudah dan fasilitas kota yang memadai.

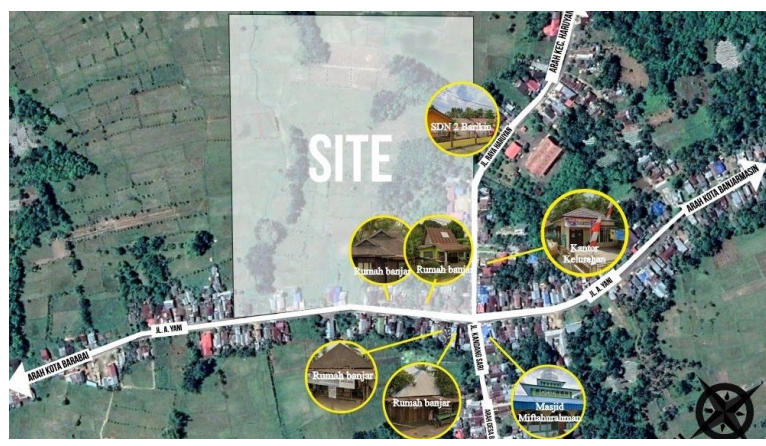

Gambar 1. Lokasi Tapak

Sumber: Analisis Pribadi (2020)

\section{B. Konsep Programatik}

Berdasarkan

permasalahan

arsitektural yaitu bagaimana rancangan pusat seni beladiri kuntau khas Banjar yang dapat mewadahi aktifitas pelatihan dan pertunjukan kuntau. maka konsep yang diterapkan adalah Konsep Cultural Education Recreation dengan pendekatan arsitektur regional berbasis vernakular. Konsep ini terdiri dari tiga hal utama yang menjadi dasar dalam perancangan pusat seni beladiri kuntau yaitu sebagai berikut :

Cultural. Yaitu Culture (budaya) khas Banjar yang diterapkan seperti kuntau khas banjar itu sendiri, tipologi bangunan dan ornamen/ukirannya.

Education. Yaitu pendidikan yang diberikan kepada para murid perguruan kuntau yang ingin berlatih kuntau dan mengembangkannya ketingkat yang lebih tinggi sebagai prestasi.

Recreation. Rekreasi in bisa dirasakan oleh pengunjung yang ingin menonton pertunjukkan kuntau dan juga para pemain kuntau yang melakukan pertunjukan kuntau.

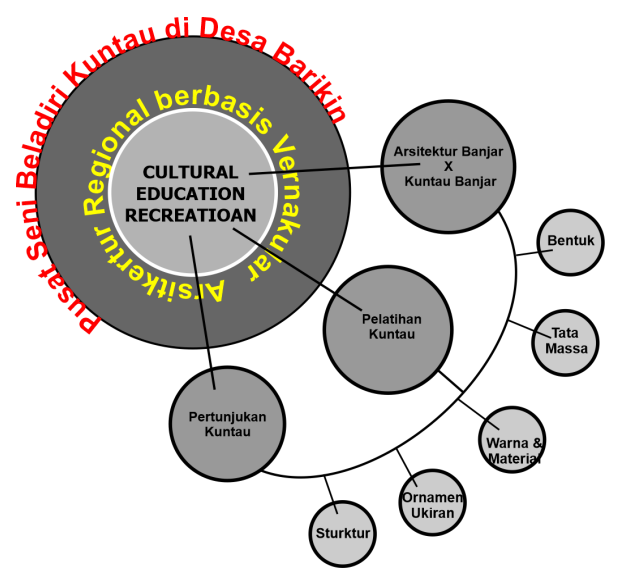

Gambar 2. Konsep Programatik Sumber: Analisis Pribadi (2020) 


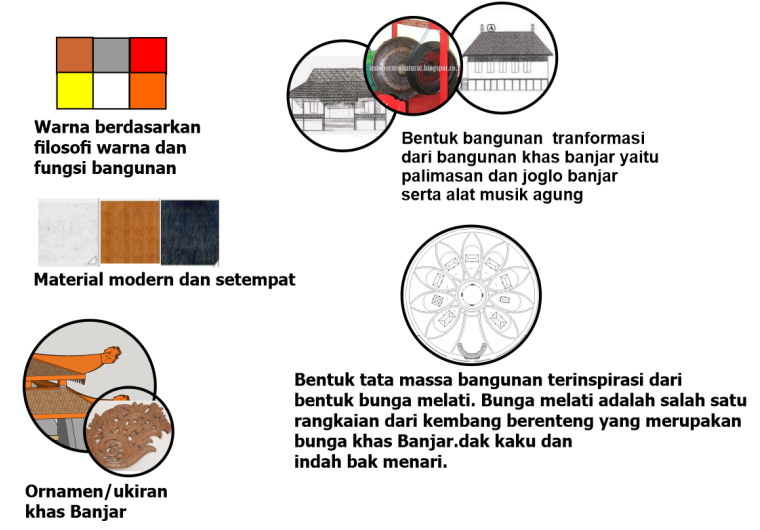

Gambar 3. Implementasi Konsep Sumber: Analisis Pribadi (2020)

\section{Konsep Rancangan}

\section{Konsep Bentuk}

Konsep bentuk bangunan mengadopsi dari rumah tradisional Banjar yaitu Palimasan dan Joglo Banjar yang ditransformasikan ke bentuk bangunan baru. 2 rumah ini dipilih dikarenakan kedua rumah tersebut memiliki bentukan dasar massa segi empat dan tidak memiliki anjung sehingga mudah diterapkan kedalam bangunan rancangan. Selain itu juga menggunakan transformasi bentuk dari alat musik Agung ke bentuk bangunan pertunjukan. Rumah Joglo Banjar juga dipilih 8 supaya mengenalkan bahwa suku khususnya kerajaan Banjar merupakan kerajaan yang memiliki keterkaitan dan kedekatan dengan kerajaan Jawa pada masa lalu dan Joglo tidak hanya identik dengan suku Jawa saja.

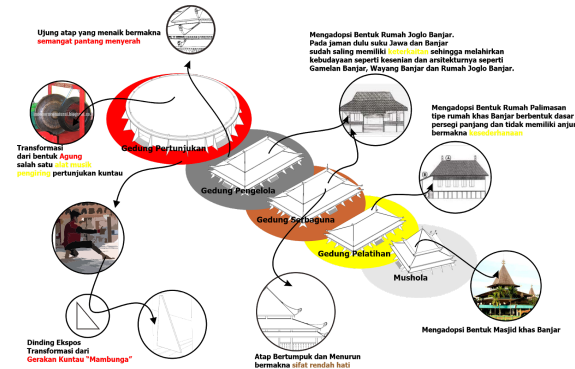

Gambar 4. Konsep Bentuk Sumber: Analisis Pribadi (2020)

\section{Konsep Tata Massa}

Bentuk tata massa bangunan terinspirasi dari bentuk bunga melati. Bunga melati merupakan salah satu dari rangkaian kembang barenteng yang merupakan bunga khas Banjar. Selain itu Bunga juga terdapat dalam istilah kuntau yaitu membunga yang merupakan salah satu gerakan atau tahap dalam bermain kuntau.

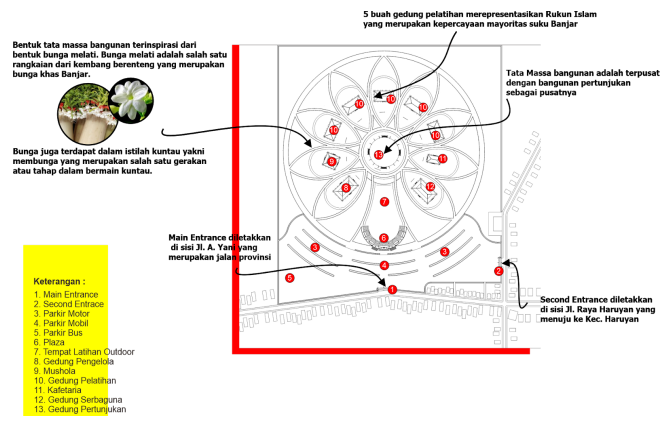

Gambar 5. Konsep Tata Massa Sumber: Analisis Pribadi (2020)

\section{Konsep Ornamen dan Ukiran}

Ornamen dan ukiran juga mengambil dari arsitektur Banjar yaitu papilis,pagar bular dan jamang yang diterapkan ke massa bangunan. Serta terdapat juga pintu setinggi $150 \mathrm{~cm}$ yang mana jika digunakan membuat orang menunduk yang mencerminkan sifat rendah hati. 


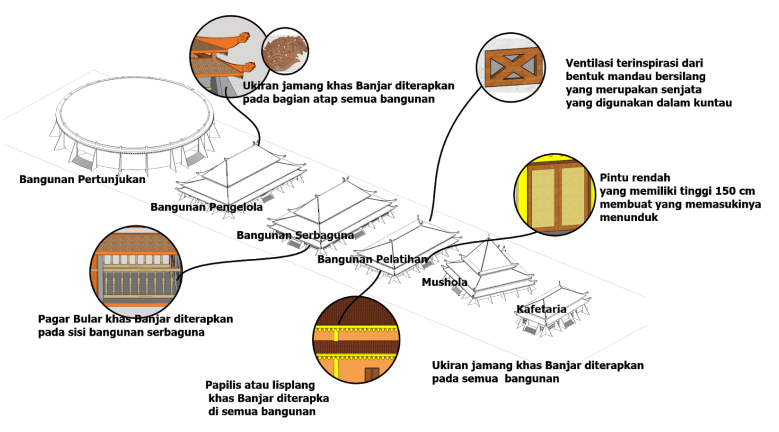

Gambar 6. Konsep Ornamen dan Ukiran Sumber: Analisis Pribadi (2020)

\section{Konsep Warna dan Material}

Konsep warna pada pusat seni beladiri kuntau ini menggunakan warna-warna yang memiliki nilai filosofi yang sesuai dengan bangunannya. Hal tersebut bertujuan juga sebagai pembeda antar bangunannya .

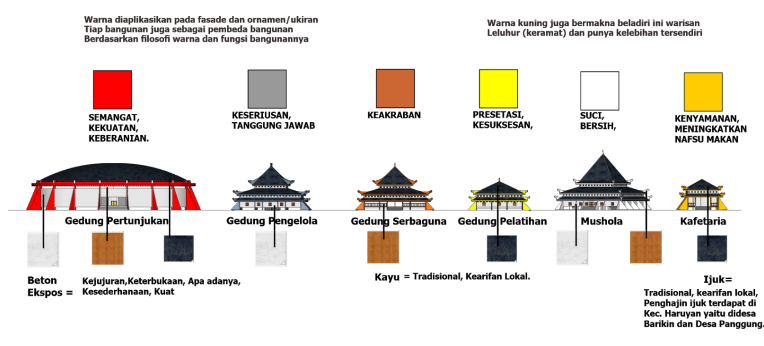

Gambar 7. Konsep Warna dan Material Sumber: Analisis Pribadi (2020)

Warna-warna tersebut diterapkan pada dinding ekspos bangunan. Warna kuning ke emasan pada gedung pelatihan bermakna prestasi dan kesuksesan sehingga diharapkan pemain kuntau yang berlatih tersebut dapat berprestasi dan meraih sukses dimasa akan datang. Warna oren pada kafetaria diharapkan memberikan kenyamanan dan meningkatkan nafsu makan saat berada di kafetaria tersebut. Warna coklat pada gedung serbaguna yang bermakna keakraban dan rasa aman ditujukan kepada semua perguruan kuntau yang ada dapat tetap menjalin silaturahim dan memperkuat keakraban. Warna abu-abu pada bangunan pengelola bermakna tanggung jawab dan keseriusan ditujukan akan pengelola dapat melaksankan tugasnya dengan penuh tanggung jawab dan keseriusan. Serta warna merah pada bangunan pertunjukan bermakna semangat, kekuatan,keberanian sehingga diharapkan pemain kuntau serta semua orang yang yang mempunyai ketertarikan terhadap kuntau menjadi semangat dalam melestarikan kebudayaan kuntau khas Banjar ini. Konsep material pada bangunan menggunakan material yang mendukung konsep arsitektur regional yaitu 9 penggabungan material modern dan setempat. Sehingga material yang digunakan berupa beton pada dinding bangunan, material kayu pada ornamen dan ukiran serta material ijuk pada penutup atap.

\section{HASIL}

Pembagian zona pada kawasan Pusat Seni Beladiri Kuntau di Desa Barikin ini dibagi atas zona venue kuntau, plaza, serta zona penunjang yang saling terintegrasi satu sama lain. Wujud identitas daerah diangkat melalui berbagai filosofi budaya kuntau dan ciri khas lokal yang diterapkan pada lansekap maupun bangunan di dalam kawasan.

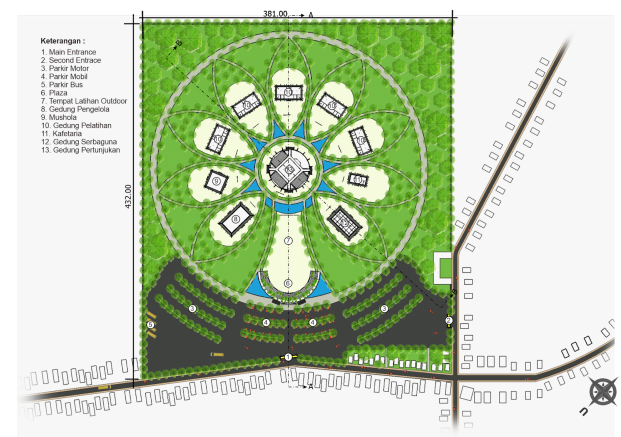

Gambar 8. Siteplan

Sumber: Analisis Pribadi (2020) 
Bentuk tata massa bangunan terinspirasi dari bentuk bunga melati. Bunga melati merupakan salah satu dari rangkaian kembang barenteng yang merupakan bunga khas Banjar. Selain itu istilah bunga juga terdapat dalam kuntau yaitu membunga yang merupakan salah satu gerakan atau tahap dalam bermain kuntau.

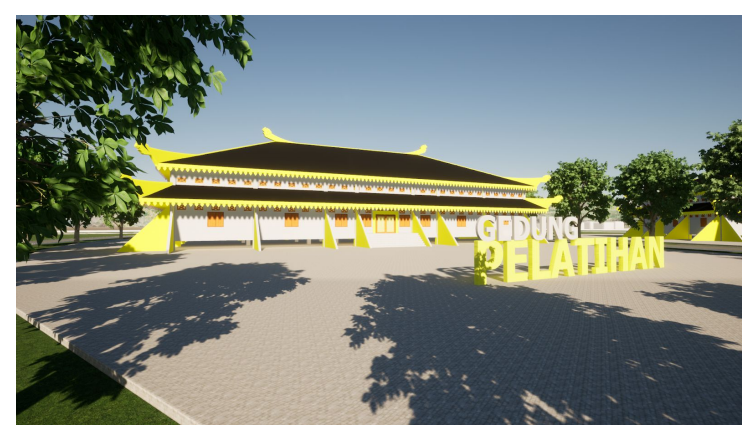

Gambar 9. Gedung Pelatihan

Sumber: Analisis Pribadi (2020)

Gedung pelatihan kuntau mamou menampung 60 orang murid setiap bangunannya. Bangunan ini mengadopsi dari bentuk rumah Palimasan Banjar. Bentuk dasar dari bangunan ini adalah persegi panjang tanpa anjung yang bermakna kesederhanaan. Atap berundak dan miring bermakna sifat rendah hati. Ujung atap yang menaik bermakna semangat pantang menyerah. Dinding ekspos merupakan tranformasi dari gerakan kuntau yaitu gerakan menyembah pada peragaan membunga kuntau. Terdapat juga ukiran jamang khas Banjar serta ventulasi dari bentuk dasar Mandau bersilang yang merupakan senjata kuntau. Kemudian terdapat pintu setinggi $150 \mathrm{~cm}$ membuat orang yang melaluinya menunduk makna rendah hati. Papilis atau lisplang khas Banjar juga diterapkan pada bangunan ini.

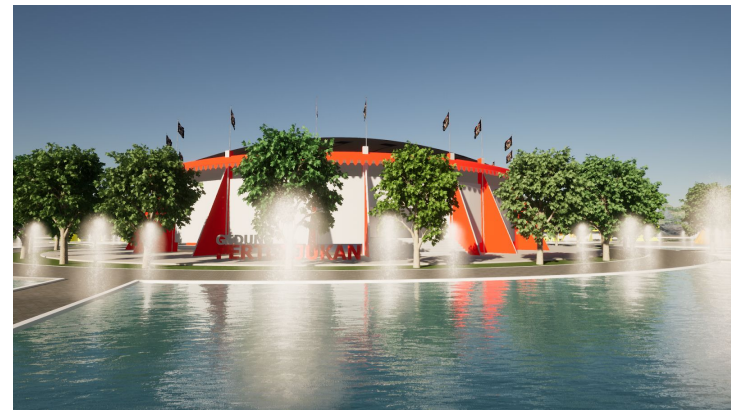

Gambar 10. Gedung Pertunjukan

Sumber: Analisis Pribadi (2020)

Gedung pertunjukan mempunyai kapasitas penonton sebanyak 1000 orang. Bangunan ini mengadopsi dari bentuk alat musik agung yakti salah satu alat musik pengiring pertunjukan kuntau.

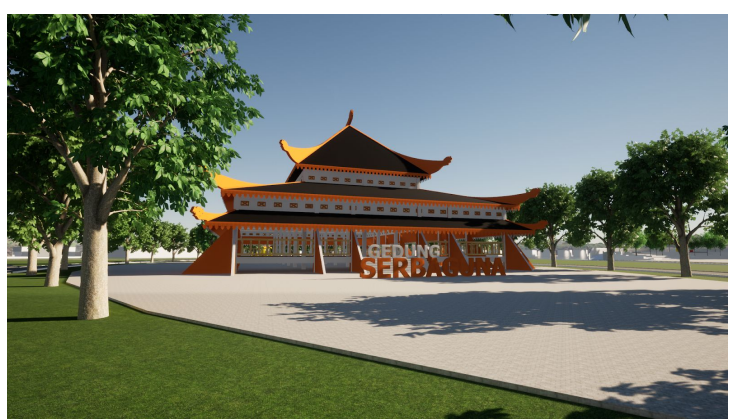

Gambar 11. Gedung Serbaguna Sumber: Analisis Pribadi (2020)

Gedung Serbaguna ini mampu menampung sekitar 500 orang. Bentuk bangunan ini mengadopsi dari bentuk rumah Joglo Banjar. Warna coklat pada bangunan bermakna keakraban dan rasa aman ditujukan kepada semua perguruan kuntau yang ada agar dapat menjaga dan menjalin silaturahim serta memperkuat keakraban. 


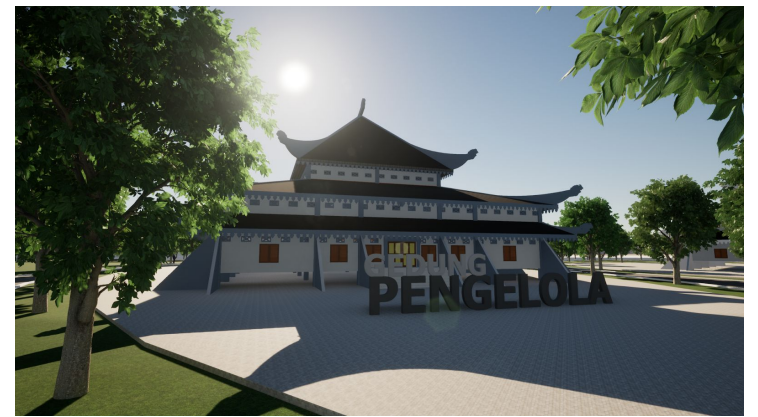

Gambar 12. Gedung Pengelola

Sumber: Analisis Pribadi (2020)

Gedung Pengelola juga mengadopsi dari bentuk rumah Joglo Banjar. Warna abu-abu pada bangunan bermakna tanggung jawab dan keseriusan, hal ini ditujukan kepada pengelola agar dapat melaksanakan tugasnya dengan penuh tanggung jawab dan keseriusan.

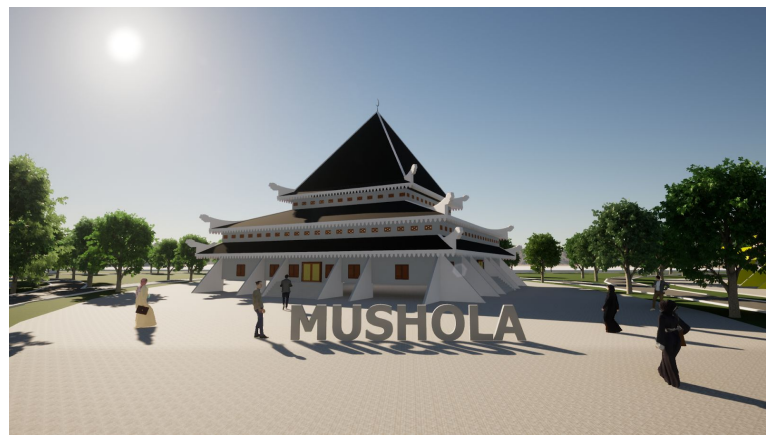

Gambar 13. Mushola

Sumber: Analisis Pribadi (2020)

Mushola bentuknya mengadopsi dari bentuk karakteristik masjid khas Banjar. Mushola ini mampu menampung kurang lebih 100 jamaah.

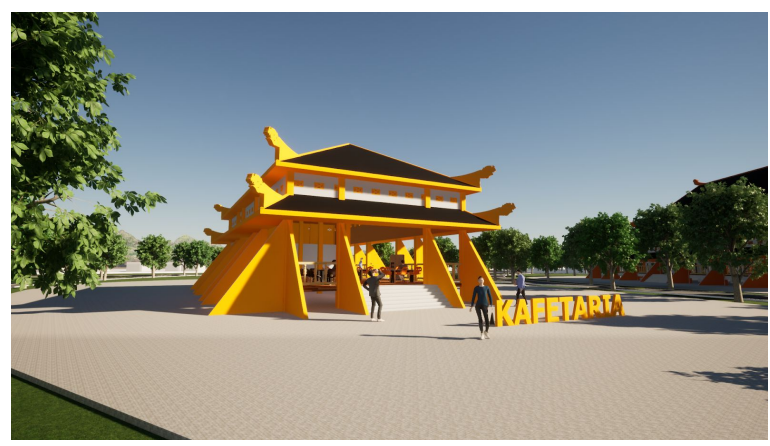

Gambar 14. Kafetaria

Sumber: Analisis Pribadi (2020)

Kafetaria bentuknya mengadopsi dari bentuk rumah Palimasan Banjar. Warna oren pada bangunan diharapkan memberikan kenyamanan dan mengingkatkan nafsu makan saat berada di kafetaria ini.

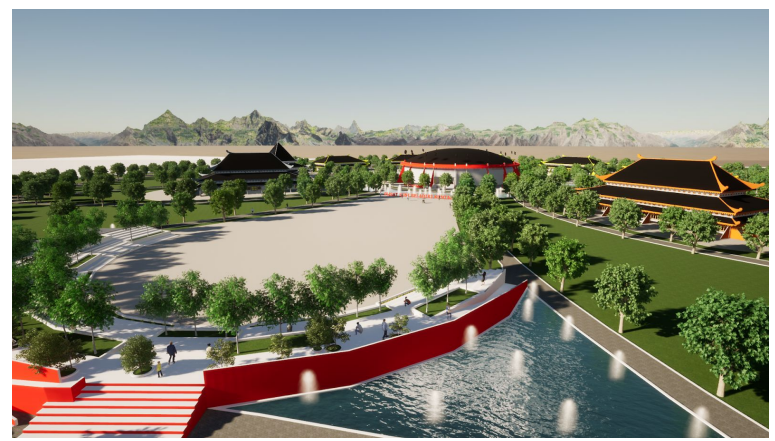

Gambar 15. Perspektif Mata Burung Sumber: Analisis Pribadi (2020)

Pada sisi depan bangunan terdapat juga plaza sebagai area untuk berlatih kuntau di luar ruangan. Terdapat juga tribun untuk pengunjung menonton latihan maupun pertunjukan kuntau.

\section{KESIMPULAN}

Pusat seni beladiri kuntau di desa Barikin merupakan bangunan yang dirancang untuk mewadahi aktifitas kuntau khas Banjar serta masyarakat yang berminat untuk mengetahui, mendalami ataupun hanya sekadar menonton pertunjukan kuntau khas Banjar.

Fokus masalah yang akan diselesaikan pada pusat seni beladiri kuntau ini yaitu bagaimana rancangan pusat seni 
beladiri kuntau di desa Barikin yang dapat mewadahi aktivitas pelatihan dan pertunjukan kuntau dengan ciri khas Banjar. Konsep yang digunakan dalam penyelesaian masalah adalah konsep Cultural Education Recreation dengan pendekatan arsitektur regional berbasis pada vernakular.

Pada pusat seni beladiri kuntau terdapat wadah pelatihan dan pertunjukan kuntau dan beberapa bangunan pendukung seperti gedung serbaguna, gedung pengelola, kafetaria dan mushola yang memiliki gaya arsitektur vernakular Banjar.

Dengan adanya pusat seni beladiri kuntau di desa Barikin ini diharapkan para pemain kuntau dapat mengembangkan kuntau dan mencetak prestasi serta menjaga kelestarian kesenian khas Banjar.

\section{DAFTAR PUSTAKA}

Referensi Buku dan Jurnal

Neufert, Ernst. (1996). Data Arsitek Edisi Pertama. Jakarta: Erlangga

Neufert, Ernst. (2002). Data Arsitek Edisi Kedua. Jakarta: Erlangga

Neufert, Ernst. (2007). Data Arsitek Edisi Ketiga. Inggris: Blackwell Science

Kompak Borneo. (2019) AD/ART Kompak Borneo. Hulu Sungai Tengah

Seman, Syamsir dan Irhamna. (2001). Arsitektur Tradisional Banjar Kalimantan Selatan. Banjarmasin: Ikatan Arsitektur Indonesia. 